\title{
ARGELIA Y LOS ESTUDIOS ÁRABES EN ALICANTE (II): MARÍA JESÚS RUBIERA
}

\author{
ISAAC DONOSO \\ Universidad de Alicante
}

I

Junto con Míkel de Epalza, María Jesús Rubiera Mata (1942-2009) fue la arabista que dio forma a la tradición de nuestros estudios en la Universidad de Alicante. En tal sentido se le realizó un número homenaje en la revista Sharq Al-Andalus, donde pueden encontrarse sus aportaciones a diferentes líneas de investigación en las que, sus contribuciones, fueron decisivas para el avance científico: origen y naturaleza de las jarchas, la poesía epigráfica de la Alhambra, la literatura andalusí, y la cultura de mudéjares y moris $\cos ^{1}$. Fallecida el 7 de junio del año $2009,{ }^{2}$ queremos con esta simple nota resaltar sus trabajos relacionados con Argelia y los temas argelinos.

Ciertamente no fue un tema tratado exclusivamente en su producción escrita, pero en la obra de María Jesús Rubiera encontramos materiales que han engrosado el acceso bibliográfico español a temas argelinos. El primero sería la relevancia dada al escritor tremecení del siglo XVI Abū 1-'Abbās Aḥmad al-Maqqarī y su obra Nafḥ al-țīb min guṣn al-Andalus al-rațīb wa-dikr wazìri-hā Lisān al-Dīn ibn al-Jațīb I

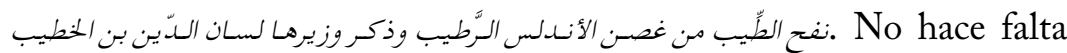
resaltar la importancia de al-Maqqarī como fuente para el conocimiento de al-Andalus y la cultura andalusí, en esta obra monumental dedicada a la memoria de Ibn al-Jațîb. Lo relevante en Rubiera es la selección y traducción de textos del autor tremecení para la confección de una obra ambiciosa - y hoy consolidada como un clásico del arabismo español- como La arquitectura en la literatura árabe. Datos

${ }^{1}$ Sharq Al-Andalus. «Homenaje/Homenatge a María Jesús Rubiera Mata», 1993-1994, núms. 10-11, 833 pp.

${ }^{2}$ Luis F. Bernabé Pons y José F. Cutillas Ferrer, "Necrológica. María Jesús Rubiera Mata (1942-2009)”, Sharq Al-Andalus, 2008-2009, núm. 19, pp. 337-349, donde se reproduce una lista con sus publicaciones. 
para una estética del placer, cuya primera edición apareció en la emblemática «Biblioteca de visionarios, heterodoxos y marginados» de la Editora Nacional en 1981. Así se describía en el glosario al personaje:

AL-MAQQARİ: Historiador y literario nacido en Tlemecén en el año 1591, autor de una monumental monografía sobre al-Andalus, titulada Nafh al-Tī b, en la que hay toda clase de materiales históricos, literarios, geográficos, etc ${ }^{3}$.

Sin duda la obra de al-Maqqarī está en los orígenes del arabismo español, sobre todo desde que Pascual de Gayangos (1809-1897) realizara una referencial pero incompleta versión en inglés, The History of the Mohammedan Dynasties in Spain, ${ }^{4}$ y Dozy una edición en árabe, Analectes sur l'bistoire et la littérature des arabes d'Espagne. ${ }^{5}$ No obstante, a partir de aquí se ha usado a al-Maqqarī como fuente, sin reparar mucho en su faceta como autor argelino, como intelectual magrebí que algo tiene que decir, decirnos, en torno al desarrollo cultural de Tremecén y el territorio argelino en el siglo XVI y comienzos del $\mathrm{XVII}^{6}$. Rubiera resalta esta faceta de al-Maqqarī para el conocimiento de la cultura árabe clásica, con un buen número de citas y traducciones directas desde la edición de El Cairo de 1949, como la descripción del jardín donde fue enterrado Ibn Šuhayd:

Este jardín era para Abū 'Amīr ibn Šuhayd lugar de placer y descanso, cuando el destino colmaba sus deseos, tanto sobrio como embriagado.

Tanto él como el dueño del jardín, al-Zaŷŷālī, fueron enterrados allí.

${ }^{3}$ La arquitectura en la literatura árabe. Datos para una estética del placer. Segunda edición, aumentada. Prólogo de Antonio Fernández Alba, Madrid, Hiperión, 1988, p. 191.

${ }^{4}$ The History of the Mohammedan Dynasties in Spain; extracted from the Nafbu-t-tib min ghosni-l-andalusi-r-rattib wa tárikh Lisánu-d-Din ibni-l-Khattíb, by Ahmed ibn Mohammed alMakkari, a native of Telemsan. Translated from the copies in the Library of the British Museum, and illustrated with critical notes on the History, Geography, and Antiquities of Spain, by Pascual de Gayangos, member of the Oriental Translation Committee, and late Professor of Arabic in the Athenaeum of Madrid, Londres, Oriental translation fund of Great Britain and Ireland, 184043, 2 vols. Existe una moderna reproducción facsímil con introducción por parte de Michael Brett, Londres, Routledge, 2002.

${ }_{5}^{5}$ Analectes sur l'histoire et la littérature des arabes d'Espagne par al-Makkari, publiés par $R$ Dozy, G. Dugat, L. Krehl and W. Wright, Leiden, Brill, 1855-61, 2 vols.

${ }^{6}$ Véase Mourad Kacimi, "Abū-l-'Abbās Aḥmad Ibn Muḥammad al-Maqqarī al-Tilimsān̄̄: su vida, formación y obras”, Revista Argelina, 2015 (otoño), núm. 1, pp. 61-77. No obstante, sin duda es personaje bien conocido en la bibliografía árabe, como en Muhammad 'Abd al-Karīm, Al-Maqqarī wa-kitābu-bū Naf̣̣ at-țīb, Beirut, Dār Maktaba al-ḥayāt, 1981, 519 pp. 
Compañeros en su despreocupación juvenil, camaradas de borracheras en las que se entregaban con afán al vino, se comportaban con fatuidad y orgullo hasta que llegó su perdición. A la hora de la muerte estuvieron unidos como lo habían estado en vida ${ }^{7}$.

Rubiera cita y traduce constantemente a al-Maqqarī, no vamos aquí a repetir las citas. Quede simplemente como testimonio de la relevancia del autor tremecení en la recopilación y pervivencia de un mundo cultural que ya sólo podía expresarse en el exilio, y como componente que irremediablemente iba a insuflar las culturas magrebíes. Al-Andalus vivía su último florecimiento cultural, pero ya no en tierras peninsulares, sino en el norte de África, Fez, Tetuán, Sargel, Testur, y también Tremecén.

\section{II}

Una contribución más visible de María Jesús Rubiera a los estudios sobre Argelia se produjo en el singular volumen bajo su coordinación titulado Carlos V, los moriscos y el Islam, aparecido en el año 2001 y publicado por la Sociedad Estatal para la Conmemoración de los Centenarios de Felipe II y Carlos V. El libro llevaba por portada el famoso tapiz de la conquista de Túnez por Carlos V (1535) - que se encuentra, que sepamos, en los Reales Alcázares de Sevilla-, el cual está invertido y África aparece como una gran masa de tierra sobre la Península. Ésta fue una idea de Míkel de Epalza, para demostrar la diferente percepción que se tiene del espacio, también del espacio geográfico, y el uso ideológico que se hace de la cartografía. En el púlpito del tapiz se puede leer:

Porque la conquista que Carlos Emperador de Romanos quinto deste nombre y primero entre los Reyes de España: hizo en África el año de MDXXXv tuvo causas graves y de mucha necessidad: Las quales los Coronistas de su tiempo declaran más copiosamente en sus historias. Aquellas dexadas aparte: sólo se figura en esta obra la semejança del hecho quanto más al propio fue possible. $\mathrm{Y}$ porque para bien entenderlo conviene tener noticia de las regiones $y$ provincias en que los negocios passaron y donde los aparejos se

\footnotetext{
${ }^{7}$ La arquitectura en la literatura árabe, loc. cit., 1988, p. 82.
} 
proveyeron: en este paño se tratará dello tan al natural que ninguna cosa tocante a la Cosmografía se pueda desear assí en las costas de África: como en las de Europa y sus fronteras: declarando la forma dellas con sus puertos principales: vaíos: islas: vientos: e las mismas distancias que se hallan: Teniendo mucho más respecto a la precisión de su assiento: que a la propiedad de la pintura. Y assí como esto se ha hecho en lo de la mar conforme a la Cosmografía: assí en lo de la tierra el pintor ha observado lo que a su arte se deve. Considerando el que lo mirare que lo vee desde Barcelona donde se començó la navegación para Túnez. La qual es entre levante y medio día: dexando el norte detrás sobre el hombro izquierdo. Pues fundados en esta verdad: se pueden después mejor entender las particularidades de los otros tapizes y el sitio de aquellas partes do passó lo que en ellos se contiene.

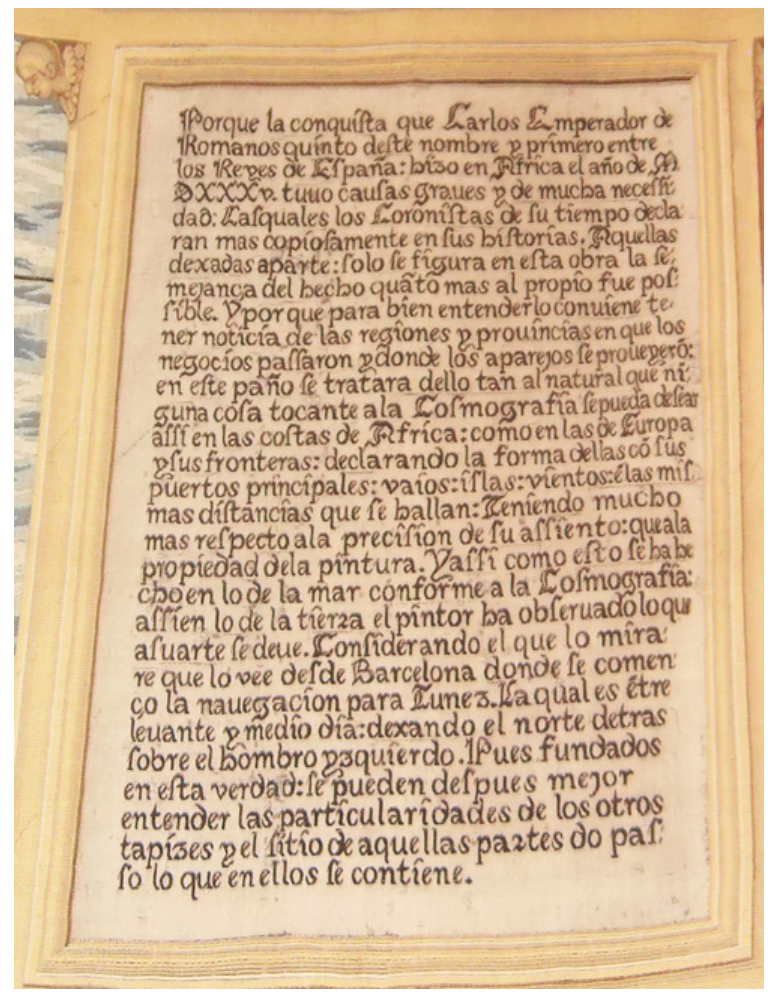

Detalle del Tapiz de la Conquista de Túnez por Carlos V. Real Alcázar, Sevilla [Foto I. Donoso] 
La idea de nuevo era resaltar la particularidad africana en relación al contexto mediterráneo, $\mathrm{y}$ la diferente perspectiva si se ve el mundo desde la otra orilla. Tanto Míkel de Epalza como María Jesús Rubiera siempre han incitado la multiplicidad y polisemia del objeto de estudio a través de las miradas cruzadas, y el tapiz es una verdadera alegoría de esta hermenéutica. Lo mismo puede decirse del volumen, que fue resultado de un congreso internacional de idéntico título celebrado en la Universidad de Alicante del 20 al 25 de noviembre del año 2000. Con estas palabras introduce Rubiera los motivos del proyecto, y la necesidad de ver la expansión imperial de la Monarquía Hispánica de los Habsburgo con los ojos de los musulmanes peninsulares y norteafricanos para una mejor comprensión del contexto histórico y humano:

Durante el año 2000 se han sucedido una serie de eventos culturales -congresos, exposiciones - para conmemorar el centenario del nacimiento de Carlos V con el patrocinio de la Sociedad Estatal para la Conmemoración de los Centenarios de Felipe II y Carlos V. El nuestro es el último de ellos (Alicante, 20-25 de noviembre) y ha tratado de acercarse a la figura del Emperador desde un ángulo muy específico, desde la visión que de él tenían los musulmanes de su época, que no fueron «convidados de piedra» en las actividades de Carlos V, puesto que como súbditos suyos - los mudéjares de Aragón y Valencia - constituían un problema ante su imagen de «campeón de la cristiandad» y de ahí, la obligada conversión de ambas comunidades, o como cristianos oficialmente, seguían siendo de hecho musulmanes los granadinos, que según Antonio de Guevara: «todos eran muy finos moros y en veintisiete años que eran bautizados, no hallaron veintisiete que fuesen bautizados», o aquellos moriscos y mudéjares que, emigrados, fueron un importante baluarte de la recién nacida Argelia con Barbarroja y los otomanos. Éstos son un capítulo aparte, puesto que eran la gran potencia islámica del Mediterráneo, la antagonista por excelencia del Imperio de Carlos $V$ tanto por mar como por el Danubio [...] Nuestro objetivo de escuchar la voz de los musulmanes frente a sus interlocutores cristianos no es un hecho novedoso en nuestro grupo investigador de la Universidad de Alicante. En primer lugar, como arabistas nuestra función de siempre es estudiar lo que a lo largo de siglos han dicho los textos árabes, y, en segundo lugar, desde hace un tiempo, escuchar la voz de los mudéjares y moris- 
cos, a los que la mayor parte de la historiografía, numerosa y excelente, por otro lado, ha tenido tendencia a cosificar ${ }^{8}$.

El volumen se organiza en tres grandes bloques: Los moriscos en España (con nueve contribuciones); Magrebíes, moriscos y otomanos (siete capítulos); y Shiíes y luteranos (dos textos). La segunda parte se dedica, prácticamente en su totalidad, a las relaciones hispano-argelinas de la época: "La ocupación del Magreb por Hayreddīn Barbarroja según el Ms. 2459 de la Üniversite Kütüphanesi de Estambul” (Miguel Ángel de Bunes Ibarra); "Papel político de los moriscos en el nacimiento de la Argelia moderna en tiempos de Carlos V" (Míkel de Epalza); "Tres historiadores y políticos de Argelia presentan la política de Carlos V con la naciente Argelia moderna: Az-Zahhar (m. 1872), Zavala (1886) y Al-Madanī (m. 1983)” (Míkel de Epalza); "Charles Quint et sa politique nord africaine dans les «écrits» algériens" (Kamel Filali); "Charles Quint aux yeux des Ottomans" (Alain Servantie); "Carlos V y la Berbería. El contexto de la frontera mediterránea en la época de Carlos V” (Emilio Sola). Con investiga-dores de primera línea, y trabajos que el tiempo ha demostrado fundamentales en la bibliografía reciente, la obra coordinada por Rubiera es una aportación muy relevante al cambio de perspectiva de las relaciones entre las dos orillas, y el papel necesariamente protagonista que la perspectiva argelina tiene que reivindicar para poder entender correctamente el contexto mediterráneo.

III

Finalmente hay que destacar una obra, exquisita en su confección e impresión, con espléndidas guardas en papel coloreado, papel ahuesado con alto gramaje, portada sobria en color rubí y lomo en tabaco. Una verdadera joya bibliográfica que, sin embargo, no ha tenido demasiada distribución. Se trata de Cervantes entre las dos orillas, editado por Rubiera y publicado en la Universidad de Alicante en el año 2006. Se trata de un libro de similares características al anterior, ya

${ }^{8}$ M. a J. Rubiera Mata, "Introducción", en idem. (coord.), Carlos V, los moriscos y el Islam, Madrid, Sociedad Estatal para la Conmemoración de los Centenarios de Felipe II y Carlos V \& Universidad de Alicante, 2001, pp. 11-12. 
que nade de la conmemoración del «IV Centenario de la publicación de El Quijote», y tiene como fin estudiar la figura de Miguel de Cervantes desde la otra perspectiva, desde la otra orilla, desde el punto de vista, sobre todo, argelino:

Recogimos el guante que nos lanzaban [...] con nuestro propio color, es decir, con nuestro punto de vista, que era, sin ninguna duda, Cervantes y el Islam, para llevar a cabo un seminario que se tituló Cervantes entre las dos orillas, que se refiere a un término clásico en la historiografía andalusí: las idwatayn, al-Andalus y el Magreb, que tan bien ha analizado otro miembro de nuestro grupo investigador, porque Miguel de Cervantes fue un hombre entre las dos orillas, considerando que al-Andalus no es sólo Andalucía sino toda la Península Ibérica, y que el Magreb no es sólo Marruecos sino la península que proyecta el continente africano sobre el Mediterráneo, hoy Marruecos, Argelia y Túnez. Cervantes estuvo en Lepanto, en medio de la mar, y en sus dos orillas, Argel y España9.

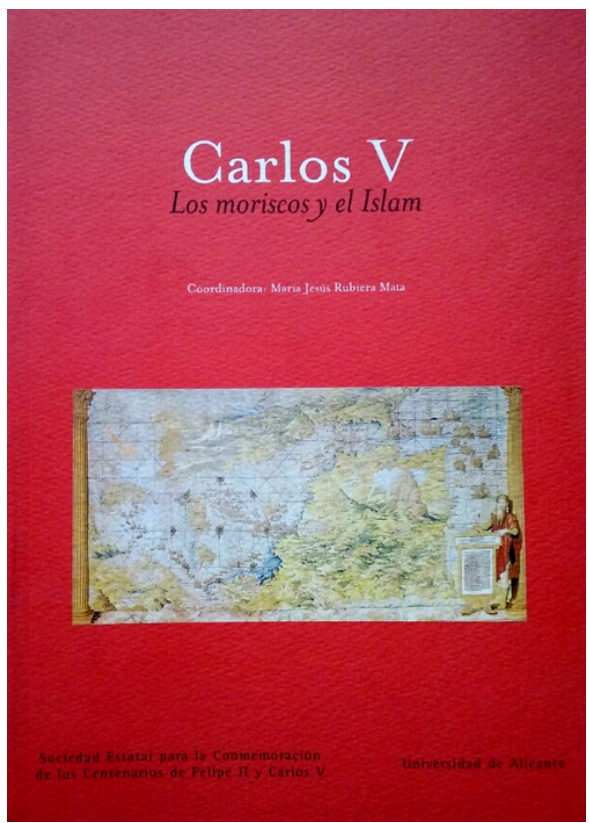

${ }^{9}$ M. a J. Rubiera Mata, "Las dos orillas cervantinas. A modo de introducción con addenda", en idem. (ed.), Cervantes entre las dos orillas, Alicante, Universidad de Alicante, 2006, pp. 9-10. 
El libro está compuesto por la introducción más cinco capítulos, casi todos ellos realizados por arabistas del grupo de investigación de la Universidad de Alicante, salvo el último, compuesto por André Stoll con su particular estilo barroco y transversal: "Felices encuentros con el manuscrito árabe de Cide Hamete Benengeli o Momentos fundacionales de una escritura «mestiza». Don Quijote, revisitado junto con el Inca Garcilaso de la Vega". Salvo este último trabajo, y el escrito por Hany El Erian El Bassal sobre la escasa fortuna editorial del Quijote en lengua árabe, los restantes capítulos tienen como centralidad Argelia: "Cervantes y el islam: una revisión historiográfica" (Luis F. Bernabé Pons); "La naturaleza de la lengua franca de Argel y Cervantes" (Mikel de Epalza); "Cervantes y el mar" (Francisco Franco-Sánchez).

Epalza ha contribuido decisivamente al mejor entendimiento de la lingua franca. El texto aquí presentado discute las referencias que se dan a las lenguas de Argel en los siglos XVI y XVII, sobre todo en la Topografía e historia general de Argel (1612), que atribuye al que llama "Pseudo-Haedo", o Antonio de Sosa, indistintamente, quien señala que "tres son las lenguas que ordinariamente se hablan en Argel". Para ello edita y comenta los textos básicos aparecidos en Sosa y Cervantes, más algunos posteriores franceses menos $\operatorname{conocidos}^{10}$. La conclusión de Epalza es que el pidgin fue una construcción de los musulmanes, y no de los cristianos o europeos que vivían en las plazas norteafricanas, una construcción precisamente para entenderse con los europeos, con los francos. A todo ello ayudó el gran número de musulmanes capaces de hablar lenguas europeas, sobre todo el español, bien moriscos bien renegados, incluso sefardíes. El capítulo de Luis Bernabé se divide en tres grandes temáticas: El cautiverio en Argel; Cide Hamete Benengeli y el modelo del Quijote; y Presencia y función de los moriscos en la obra de Cervantes. Sobre todo, y aparte de muy agudas reflexiones, es una inmensa fuente de referencias y fichas bibliográficas, por lo que constituye un magnífico texto para conocer el estado de la cuestión en los tres temas tratados. Finalmente el tra-

\footnotetext{
${ }^{10}$ A pesar del magnífico trabajo en todos los aspectos, la reedición de los textos por Epalza no está libre de errores, al menos uno notable, pues donde dice: "Y tanto que hay cuatro leguas de Argel: los que son qabayles", debe decir "Y tanto que, a cuatro leguas de Argel, los que son cabayles". La mala lectura le lleva a anotar al pie: "Corregir. «lenguas», es decir, según el español del siglo XVI, «hay cuatro grupos lingüísticos de argelino»", en ibid., p. 94.
} 
bajo de Franco-Sánchez, el más extenso, revisa de forma detallada la biografía de Cervantes, cuestionando muchas de las disculpas que se han tenido con su figura, y analiza, de forma minuciosa y a través de toda la producción cervantina, la presencia del mar y de la vida marítima, con el fin de presentarnos a un Cervantes menos reivindicado, el del ser libre que vuela como el viento, tal como lo señalara Azorín (texto azoriniano que Franco reproduce):

No volverán aquellas horas, No importarán nada los libros al lado de aquellas horas. Vivir en peligro es - cuando por motivo heroicoalcanzar la plenitud de la personalidad. Y esa plenitud la ha alcanzado Cervantes en el mar, en el Mediterráneo ${ }^{11}$.

Sirvan estas pequeñas notas para resaltar el papel que la obra de María Jesús Rubiera, si no directamente, al menos sí en la composición de unas líneas de trabajo, un equipo de investigación, unas publicaciones y, en suma, una escuela, ha tenido para el mejor conocimiento del mundo argelino en España; indiscutiblemente, la capacidad de transcender las ideas convencionales para darle la vuelta al objeto de estudio.

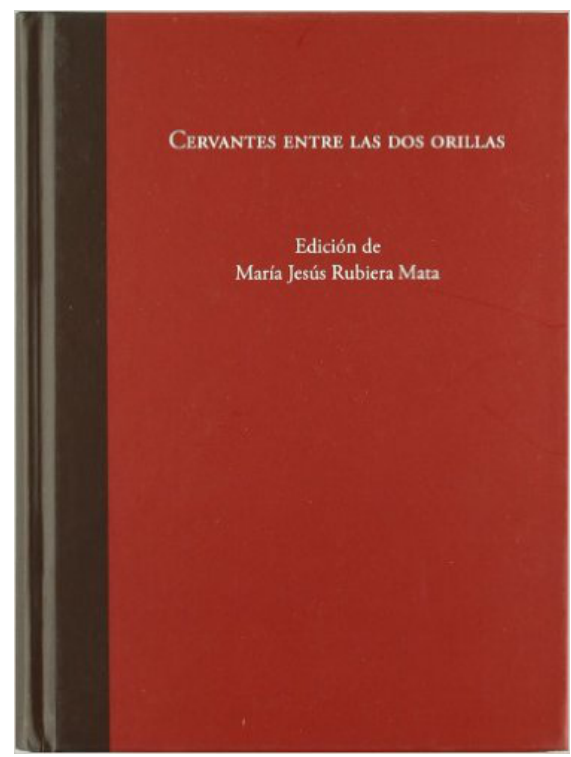

${ }^{11}$ Ibid., p. 182. 